\title{
Opioid Free Anesthesia in Patients Undergoing Three-Port Laparoscopic Cholecystectomy
}

Horia Ahmad Frran' ${ }^{1}$ MD, Manal Foad Abd-Elmoniem ${ }^{1, *}$ MD, Sawsan Soliman² MD and Mohamed Omar Alfy ${ }^{2}$ MD. $^{2}$

\author{
*CorrespondingAuthor: \\ Manal Foad Abd-Elmoniem \\ d_taha66@yahoo.com \\ Received for publication January 7 , \\ 2020; accepted February 2, 2020; \\ Published on line February 14, \\ 2020.
}

Copyright 2020 The Authors published by Al-Azhar University, Faculty of Medicine, Cairo, Egypt. All rights reserved. This an openaccess article distributed under the legal terms, where it is permissible to download and share the work provided it is properly cited. The work cannot be changed in anyway or used commercially.

doi: 10.21608/aimj.2020.22111.1059

${ }^{1}$ Anesthesiology and Intensive care Department, Faculty of medicine for girls, Al-Azhar University.

${ }^{2}$ General Surgery Department, Faculty of medicine for girls, AlAzhar University

\begin{abstract}
Background: After considerable experience with laparoscopic cholecystectomy (LC) using four ports, Authors began the three-port LC. Opioid free anesthesia OFA means a technique in which no intraoperative opioid is administered through any route.

Objectives: Study aims to assess both of the safety while using 3 ports during the laparoscopic cholecystectomy procedures and the efficiency of the Opioid Free Anesthesia throughout the perioperative period.

Patients and Methods: Patients were scheduled for elective laparoscopic cholecystectomy and classified randomly into two groups, each one contained 25 patients. Group one has submitted for Opioid Based Anesthesia protocol and group two has submitted to Opioid Free Anesthesia protocol. Surgical technique was Laparoscopic cholecystectomy and it was first tried by 3 port then the fourth port is inserted when indicated.

Results: Three-port LC successfully performed in $92 \%$ of cases of the study with safety. There were a statistically significant decrease in perioperative HR, and MAP. Study showed decrease in VAS score, post-operative Pethidine consumption and PONV. No major postoperative complications, as bile leakage or bleeding have been reported.

Conclusion: Three-port LC is a safe and technically feasible. Also OFA is superior to (OA) in anesthesia of patients undergoing LC.

Keywords: Fentanyl; Opioid free; Laparoscopic cholecystectomy; Three-ports

Disclosure: The authors have no financial interest to declare in relation to the content of this article. The Article Processing Charge was paid for by the authors.

Authorship: All authors have a substantial contributions to the article.
\end{abstract}

\section{INTRODUCTION}

Laparoscopic cholecystectomy became rapidly the procedure of choice for gallbladder disease ${ }^{1}$. It decreases postoperative pain, decreases the need for postoperative analgesia, shortens the hospital stay from 1 week to less than 24 hours, and returns the patient to full activity within 1 week (compared with 1 month after open cholecystectomy). LC also provides less scars and improved patient satisfaction as compared with open cholecystectomy. ${ }^{2}$

The origin of pain after LC is multifactorial -pain arising from incision sites i.e., somatic pain, pain from gall bladder bed i.e., visceral pain and referred pain to shoulder. The most explainable cause for visceral and shoulder pain is peritoneal distension and visceral irritation caused by the creation of pneumoperitoneum and surgical handling. ${ }^{3}$

Shoulder tip pain appearing after LC, a major aspect of total abdominal pain, is the result of diaphragmatic stretching by the pneumoperitoneum, leading to phrenic nerve neuropraxia and the stimulation of subdiaphragmatic fibers with local inflammatory stimuli such as chemical irritation, ischemia, and compression. $^{4}$
Several methods have been reported to decrease pain in the postoperative period such as: giving a local anesthetic at the site of the trocars, injection of a local anesthetic intraperitoneal, intermittent administration of non-steroidal anti-inflammatory drugs, opioids, decrease pressure during Pneumoperitoneum and decrease the numbers of operating ports 5 .Opioids have known side effects, like respiratory depression, postoperative nausea and vomiting, pruritus, difficulty in voiding, and ileus. These complications may lead to a prolonged hospital stay. High dose opioids can also cause acute opioid tolerance and hyperalgesia ${ }^{6}$.

Opioid free anesthesia OFA is a technique in which no intraoperative opioid administered through any route, including systemic, neuraxial, or tissue infiltration ${ }^{4}$. The number of case reports and small prospective studies from all over the world supports its benefits, especially in the morbidly obese population. ${ }^{7,8}$

Initially, OFA depends on combinations of non-opioid agents and adjuncts, including propofol, lidocaine, magnesium, dexmedetomidine, and ketamine to produce anesthesia, and analgesia? .

Aim of the study is to Compare OFA with Opioid anesthesia (OA) as regards hemodynamic (primary outcome). Postoperative VAS, Total Pethidine consumption 
in $24 \mathrm{~h}$ postoperative, Postoperative complications as nausea, vomiting, bradycardia, hypoxia, and shivering. (Secondary outcome).

\section{PATIENTS AND METHODS}

This randomized, prospective double-blind clinical study was carried at Al-Zahraa university hospital, Cairo, Egypt, between August 2018 to August 2019. After obtaining approval from the hospital ethical committee.

Written informed consents were obtained from 50 patients who were scheduled for elective laparoscopic cholecystectomy (informing about the laparoscopic procedure, its complications, and the need, if necessary, for conversion to open cholecystectomy), both sexes Patients were aged between 21 and 70 years, with ASA I or II. Exclusion criteria Patients who refused to participate in the study, (ASA) physical status $\geq 3$ e.g. cardiac disease, BMI $>35 \mathrm{Kg} / \mathrm{m}^{2}$ allergy to the drugs used in the study pregnant woman, history of alcohol or drug abuse, uncontrolled diabetes mellitus, Patients currently on anti-hypertensive drugs., patients with unstable cardiorespiratory disorder, patients with hepatic and renal insufficiency.

Patients were classified randomly by computergenerated random number into two groups each group contains 25 patients:

Group (I): Opioid Based Anesthesia:

Pre-induction of general anesthesia bolus of $2 \mathrm{ug} / \mathrm{kg} / \mathrm{IV}$ Fentanyl -(sunny pharmaceutical Egypt Company under License of Hameln pharmaceutical Germany) was administered then infusion of $1 \mathrm{ug} / \mathrm{kg} / \mathrm{h}$ was given intraoperatively to maintain the change in hemodynamics within $20 \%$ of the baseline.

Group (II): Opioid Free Anesthesia:

Pre-induction of general anesthesia $1000 \mathrm{mg}$ paracetamol (Pharco B international pharmaceutical-Egypt) and dexamethasone $0.1 \mathrm{mg} / \mathrm{kg}$. Lidocaine $1 \mathrm{mg} / \mathrm{kg}$ (Alexandria co. for pharmaceutical and chemical industries-Egypt), ketamine $0.5 \mathrm{mg} / \mathrm{kg}$ were given I V bolus dose. Then continuous infusion with lidocaine $2 \mathrm{mg} / \mathrm{kg} / \mathrm{hr}$ and magnesium sulfate (Manufactured by E.I.P.I.CO-. Egypt).1.5 g/hr was started. Local infiltration of skin incision with $025 \%$ bupivacaine at the end of the operation (Sunny pharmaceutical -Egypt).

\section{The technique of laparoscopic cholecystectomy}

General anesthesia was given to all the patients with routine premedication. The patient was placed in a reverse Trendelenburg position and rotate the operating table with the left side down which improves diaphragmatic function and respiratory status. During laparoscopy intra-abdominal pressure was adjusted to $12 \mathrm{mmHg}$ by continuous $\mathrm{CO}_{2}$ insufflation.

Pneumoperitoneum was created and gall bladder was dissected out from its bed by blunt and sharp dissection and was removed from the subcostal port.

All patients coming to the Surgical Out-Patient Department with benign Gall Bladder disease were admitted to the surgical ward 2 days before the laparoscopic cholecystectomy. For all patients undergoing laparoscopic Cholecystectomy following preoperative preparation was done including history, clinical examination including airway assessment, complete laboratory investigations, abdominal ultrasonography, X-ray chest, ECG.
All patients must be fasted six hours before surgery for solids and two hours for clear fluids. In the preanesthetic holding area, two cannulae were inserted to all patients, an intravenous wide bore cannula (18G) was inserted and another intravenous cannula (20G) was obtained for infusion of the studied drugs. Patients were instructed to use the visual analogue scale (VAS) for pain assessment postoperativelyl" representing "no pain" and " 10 " representing "The Worst Pain Imaginable".

While shifting the patient to the operating room, resuscitating drugs must be available, all patients have received $50 \mathrm{mg}$ Ranitidine as an $\mathrm{H}_{2}$ receptor antagonist, 10 $\mathrm{mg}$ Metoclopramide and $10 \mathrm{ml} / \mathrm{kg}$ of lactated Ringer's solution, provided patient's fasting hours was calculated and the deficit was administrated. Intraoperative monitoring includes ASA standard monitoring by Drager (Infinity Vista XL) monitor manufactured by (Drager medical system, Inc. Telford, PA18969-1042 USA); Electrocardiography (ECG), noninvasive blood pressure, pulse oximetry for $\mathrm{O} 2$ saturation, end-tidal $\mathrm{CO}_{2}$ values by capnography. Bispectral index for the depth of anesthesia.

All Patients of both groups were pre-oxygenated for 5 minutes before induction and administration of midazolam $0.05 \mathrm{mg} / \mathrm{kg}$ anesthesia were induced with $2 \mathrm{mg} / \mathrm{kg}$ i.v. propofol, cisatracurium $(0.1 \mathrm{mg} / \mathrm{kg}$ i.v. $)$ to facilitate endotracheal intubation, with the infusion of the drugs according to groups of patients were chosen.

Maintenance; boluses of cisatracurium to provide optimal surgical conditions and sevoflurane $2-4 \%$, inhalation based on BIS value between $50 \%$ and $60 \%$, to maintain mean arterial pressure (MAP) within $20 \%$ of the baseline value, the ventilation was achieved with a volume-controlled mode ventilation, respiratory rate adjusted according to $\mathrm{Et} \mathrm{CO}_{2}$ to range between $35-45 \mathrm{mmHg}$, a tidal volume of $8-10 \mathrm{ml} / \mathrm{kg}$ and mixture of gases in proportion $50 \%$ oxygen and $50 \%$ air, with PEEP $5 \mathrm{~cm} \mathrm{H} \mathrm{H}_{2} \mathrm{O}$ with using a closed circle system with a total fresh gas flow rate of $3 \mathrm{~L} / \mathrm{min}$.

After removal of the gallbladder, continuous IV infusions in both groups were stopped. After suturing of the skin local infiltration of skin incision with $025 \%$ bupivacaine. When MAP below $60 \mathrm{mmHg}$, ephedrine given 5-10 mg per dose and when bradycardia occur HR below $60 \mathrm{~b} / \mathrm{m}$ Atropine $0.1 \mathrm{mg} / \mathrm{kg}$ is given in both groups to maintain the change in hemodynamics within $20 \%$ of baseline.

At the end of procedure Neostigmine $(0.05 \mathrm{mg} / \mathrm{kg})$ with atropine $(0.01 \mathrm{mg} / \mathrm{kg}$ IV) were given to reverse neuromuscular block. After the surgery local infiltration of skin incision with $025 \%$ bupivacaine in the opioid-free group, then ETT was extubated then the patient was transferred to post anesthesia care unit (PACU). Contentious postoperative monitoring and the level of pain was assessed using the visual analogue score (VAS); Postoperative pain was treated with $1000 \mathrm{mg}$ paracetamol /8hours/IV and ketolac30 mg /12 hours/IV for the first $24 \mathrm{~h}$. If patients still complaining of pain, they were received pethidine $0.5 \mathrm{mg} / \mathrm{kg} \mathrm{IM}$, to maintain VAS scores $\leq 4$.

Demographic data: (age, sex, BMI, ASA, duration of surgery), Perioperative hemodynamic changes: MAP, HR, post-induction, after pneumoperitoneum and every $15 \mathrm{~min}$
Anesthesia

G Surgery 
till the end of surgery and 2hours postoperative, Postoperative VAS score for pain assessment, after $0 \mathrm{~h}, 2 \mathrm{hs}$, $4 \mathrm{hs}, 8 \mathrm{hs} 12 \mathrm{hs}$, and $24 \mathrm{hs}$, Total pethidine consumption in $24 \mathrm{~h}$ postoperative: $0.5 \mathrm{mg} / \mathrm{kg}$ IM guided by VAS scores. Postoperative complications as, nausea, vomiting, bradycardia, hypoxia, and shivering.

Sample size was calculated using PASS program for sample size version 11 and according to a previous study done by Mulier et al. in 2018, who reported that the mean VAS score in cases with opioid $3.3 \pm 1.2$ while in cases without opioid was found $2.3 \pm 0.8$ and by adjusting the confidence interval to $95 \%$; power of the test to $90 \%$ and the ratio between the two studied groups to $1: 1$; the total sample size needed for this study was found to be 44 cases divided equally into two groups each group 22 cases.

Data were collected, revised, coded and entered to the Statistical Package for Social Science (IBM Corp. Released 2015. IBM SPSS Statistics for Windows, Armonk, NY: IBM Corp) version 23. The quantitative data were presented in the form of mean, standard deviations and ranges when parametric, median with inter-quartile range (IQR) when non parametric and numbers with percentages for qualitative data. The comparison between two groups regarding quantitative data with parametric distribution was done by using Independent t-test while with non-parametric distribution was done by using Mann-Whitney test while the comparison between two groups regarding qualitative data were done by using Chi-square test. The confidence interval was set to $95 \%$ and the margin of error accepted was set to $5 \%$. So, the p-value was considered significant at $\mathrm{p} \leq 0.05$ considered significant-value $\leq 0.001$ was considered as highly significant-value $>0.05$ was considered non-significant.

\section{RESULTS}

AS regards Demographic data: (age, sex, BMI, ASA, duration of surgery; there was no significant difference between two studied groups (table 1).

\begin{tabular}{|c|c|c|c|c|}
\hline & $\begin{array}{l}\text { Group I } \\
25 \text { patients }\end{array}$ & $\begin{array}{l}\text { Group II } \\
25 \text { patients }\end{array}$ & $\begin{array}{l}\text { Test } \\
\text { value }\end{array}$ & P-value \\
\hline Age (Years) & $45.32 \pm 12.5$ & $\begin{array}{l}46.35 \\
10.28\end{array}$ & $0.318^{\circ}$ & 0.752 \\
\hline Sex & & & & \\
\hline Males & $15(60.0 \%)$ & $17(68.0 \%)$ & $0.347^{*}$ & 0.555 \\
\hline Females & $10(40.0 \%)$ & $8(32.0)$ & & \\
\hline $\begin{array}{l}\mathrm{BMI} \\
\left(\mathrm{Kg} / \mathrm{m}^{2}\right)\end{array}$ & $30.2 \pm 5.32$ & $32.1 \pm 7.65$ & $1.020^{\circ}$ & 0.313 \\
\hline ASA & & & & \\
\hline I & $18(72.0 \%)$ & $17(68.0 \%)$ & $0.095^{*}$ & 0.757 \\
\hline II & $7(28.0 \%)$ & $8(32.0)$ & & \\
\hline $\begin{array}{l}\text { Duration of } \\
\text { surgery } \\
\text { (min) }\end{array}$ & $\begin{array}{l}75.03 \\
12.54\end{array}$ & $\begin{array}{l}73.03 \\
10.35\end{array}$ & 0.615 & 0.541 \\
\hline
\end{tabular}

Table1: Demographic data between two studied groups (mean \pm SD) $\bullet$ : Independent t-test; *: Chi-square test
AS regards perioperative hemodynamic changes: HR \&MAP; there was a statistically significant decrease in HR and MAP in group II post-induction, after pneumoperitoneum all operative time until $1 \mathrm{hr}$ postoperative (Figure 1,2).

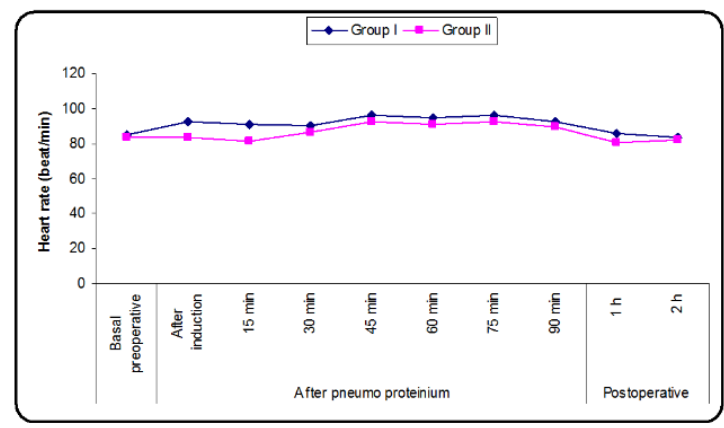

Fig. 1: Comparison between two studied groups according to HR $(\mathrm{b} / \mathrm{m})$.

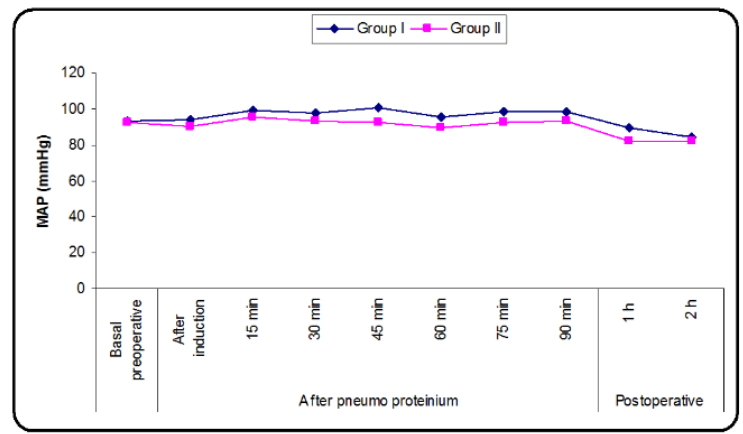

Fig. 2: Comparison between two studied groups according to MAP $(\mathrm{mmHg})$

AS regards postoperative VAS score for pain assessment, after $0 \mathrm{~h}, 2 \mathrm{hs}, 4 \mathrm{hs}, 8 \mathrm{hs}, 12 \mathrm{hs}$, and 24hs: there was a statistically significant decrease in VAS score in group (table 2).

\begin{tabular}{|c|c|c|c|c|c|}
\hline VAS score & $\begin{array}{l}\text { Group } \\
\text { I }\end{array}$ & $\begin{array}{l}\text { Group } \\
\text { II }\end{array}$ & $\begin{array}{l}\text { Test } \\
\text { value. }\end{array}$ & $\begin{array}{l}P \text { - } \\
\text { value }\end{array}$ & Sig. \\
\hline $0 \mathrm{hr}$ postop. & $4(2-7)$ & $2(1-3)$ & 3.670 & $<0.001$ & HS \\
\hline $2 \mathrm{hr}$ postop. & $5(1-8)$ & $3(1-5)$ & 5.291 & $<0.001$ & HS \\
\hline $4 \mathrm{hrs}$ postop. & $3(2-7)$ & $2(1-6)$ & 2.070 & 0.044 & $\mathrm{~S}$ \\
\hline $8 \mathrm{hrs}$ postop. & $3(1-5)$ & $2(1-4)$ & 2.318 & 0.025 & S \\
\hline 12 hrs postop. & $2(2-5)$ & $1(1-2)$ & 2.273 & 0.027 & $\mathrm{~S}$ \\
\hline $24 \mathrm{hrs}$ postop. & $2(1-4)$ & $1(1-3)$ & 4.428 & 0.001 & HS \\
\hline
\end{tabular}

AS regards total pethidine consumption in $24 \mathrm{~h}$ postoperative: $0.5 \mathrm{mg} / \mathrm{kg} \mathrm{IM}$ guided by VAS scores there were a statistically significant decrease in pethidine consumption in group II (table 3 ). 


\begin{tabular}{|c|c|c|c|c|}
\hline & $\begin{array}{l}\text { Group I } \\
25\end{array}$ & $\begin{array}{l}\text { GroupII } \\
25\end{array}$ & $\begin{array}{l}\text { Test } \\
\text { value }\end{array}$ & $\begin{array}{l}\text { P- } \\
\text { value }\end{array}$ \\
\hline $\begin{array}{l}\text { Total } \\
\text { Pethidine(mg) } \\
\text { consumption } \\
\text { in } 24 \mathrm{hrs}\end{array}$ & $\begin{array}{r}1300.85 \\
\pm 123.5\end{array}$ & $\begin{array}{l}450.32 \\
\pm 50.32\end{array}$ & $\begin{array}{l}31.889 \\
\bullet\end{array}$ & $<0.001$ \\
\hline $\begin{array}{lr}\text { Number } & \text { of } \\
\text { patients } & \text { needs } \\
\text { narcotics } & \text { and } \\
\% & \end{array}$ & $\begin{array}{l}17 \\
(68.0 \%)\end{array}$ & $\begin{array}{l}5 \\
(20.0 \%)\end{array}$ & $\begin{array}{l}11.688 \\
*\end{array}$ & 0.001 \\
\hline
\end{tabular}

Table 3: Comparison of postoperative total pethidine $(\mathrm{mg})$ consumption in $24 \mathrm{~h}$ between both studied groups mean $( \pm \mathrm{SD}) \&$ (No of patients and \%) P-value $\leq 0.001$; highly significant. Independent t-test; *: Chi-square test

AS regards postoperative complications developed in PACU; there were statistically significant decrease in numbers of patients developed nausea and vomiting in group II, while no statistically significant difference between both groups in accordance to bradycardia and no patient develop bradycardia in group II and, no patients developed hypoxia or shivering in both groups (table 4).

\begin{tabular}{|l|l|l|l|l|}
\hline & $\begin{array}{l}\text { Group } \\
\text { I } \\
\text { I }\end{array}$ & $\begin{array}{l}\text { Group } \\
\text { II }\end{array}$ & $\begin{array}{l}\text { Test } \\
\text { value* }\end{array}$ & P-value \\
\hline Nausea & $\begin{array}{l}15 \\
(60.0 \%)\end{array}$ & $\begin{array}{l}4 \\
(16.0 \%)\end{array}$ & 10.272 & $0.001^{* *}$ \\
\hline Vomiting & $\begin{array}{l}6 \\
(24.0 \%)\end{array}$ & $\begin{array}{l}1 \\
(4.0 \%)\end{array}$ & 4.153 & $0.041^{*}$ \\
\hline Bradycardia & $\begin{array}{l}1 \\
(4.0 \%)\end{array}$ & $\begin{array}{l}0 \\
(0.0 \%)\end{array}$ & 1.020 & 0.312 \\
\hline
\end{tabular}

Table 4: Comparison of complications developed in PACU between both studied group (No of patients and \%). P value $>0.05$ no significant, *P-value -value $\leq 0.05$ significant, **P-value $\leq$ 0.001 ; highly significant.*: Chi-square test

Three-port LC was successfully performed in 46 patients $(92 \%)$. Because of the poor operative field by the manipulation of the gallbladder using one grasping forceps, placement of a fourth port was required in 4 patients (8\%). We experienced no major intra-operative complications, including CBD injury. Operative bleeding was minimal. We had no major postoperative complications, such as bile leakage or bleeding.

\section{DISCUSSION}

In the era of laparoscopic surgery, less postoperative pain and early recovery are major goals to achieve better patient care and cost-effectiveness. Improvements in the technology of laparoscopic surgery made it possible to perform three-port LC. This technique was slightly difficult to perform in long gallbladders with a long peritoneal fold. This was because the fundus of the long gallbladder repeatedly fell towards the area of dissection in Calot's triangle ${ }^{10}$ When we encountered difficulty during the three-port technique (due to adhesion), we immediately inserted the fourth port to delineate the anatomy of Calot's triangle and improve the dissection.

Intra-operative infusion of Lidocaine decreased demand for opioids, reduced PONV, rapid return function of the intestine and a shortening of hospital stay ${ }^{7}$.

Magnesium sulfate is an N-methyl D-aspartate (NMDA) antagonist receptors, preventing the entry of calcium and sodium into the cell and thereby avoid the transmission of pain. Using magnesium in the intra-operative period leads to reduce the pain, PONV ${ }^{11}$. Ketamine is also an NMDA antagonist acting by blocking the release of potassium from the cell and thus prevents the transmission of painful impulses. Preemptive giving of ketamine has shown an opioid-sparing effect in the intra-operative period and decreased the need for opioids in the postoperative period ${ }^{12}$. Dexamethasone is a corticosteroid that has antiemetic and anti-inflammatory effects on the wound with less edema leads to less pain. ${ }^{13}$

Pneumoperitoneum elevated systemic vascular resistance, mean arterial pressure, cardiac filling pressure and decrease in the cardiac index also, $\mathrm{CO}_{2}$ insufflation leads to peritoneal absorbed it producing hypercarbia, which stimulates the sympathetic nervous system and thus increases BP, HR, decreased myocardial contractility and lowers arrhythmia threshold ${ }^{14}$.

The current study shows; there was a statistically significant decrease in HR and MAP in group II post-induction, after pneumoperitoneum all operative time until 1hur postoperative. The same results were documented by Gaszynski et al. ${ }^{15}$ when studied on 42 patients undergoing bariatric surgery divided into either an OFA group using dexmedetomidine or a fentanyl-based anesthetic group and they found a significant decrease in HR and MAP in OFA group Also Shalaby et al. ${ }^{16}$ found that there were significant decrease in HR and MAP in dexmedetomidine OFA group than fentanyl group after intubation, after pneumoperitoneum, until $60 \mathrm{~min}$ after induction, when studied on 80 patients scheduled for elective laparoscopic cholecystectomy.

On the other hand, Jan et al. ${ }^{17}$ showed there were no differences in HR and MAP intraoperative between OFA and opioid-based anesthesia (OA) groups when they measured quality of recovery on 50 Patients undergoing elective laparoscopic bariatric surgery. They give the patient $0.5 \mathrm{mcg} / \mathrm{kg}$ sufentanil before induction, OA group, and $0.5 \mathrm{mcg} / \mathrm{kg}$ dexmedetomidine, $0.25 \mathrm{mg} / \mathrm{kg}$ ketamine, and $1.5 \mathrm{mg} / \mathrm{kg}$ lidocaine in OFA group. This confliction may due to the sufentanil has more myocardial stability and more potent than fentanyl. The current study shows a statistically significant decrease in VAS in group II at $0 \mathrm{~h}$, $2 \mathrm{hs}, 4 \mathrm{hs}, 8 \mathrm{hs}, 12 \mathrm{hs}$ and 24 postoperative. Kataria et al. ${ }^{18}$ showed a significant decrease in VAS score in the OFA group when studied on the efficacy of dexmedetomidine versus fentanyl on the pressor response and pneumoperitoneum in laparoscopic cholecystectomy.

The results of doing by Shalaby et al. ${ }^{16}$ documented that there was a significant decrease in OFA group regarding VAS scores at 20,60 minutes and 6 hours postoperatively than the fentanyl group.

A study by Toleska and Dimitrovski ${ }^{19}$, showed that the OFA group statistically significant decrease VAS score at first hour
Anesthesia 
and 24 hours after the surgery than the Fentanyl group, also low VAS score in OFA group with the non-significant difference between two groups at other time postoperative.

The current study shows there was a statistically significant decrease in pethidine consumption in $24 \mathrm{~h}$ postoperative in group II compared to group I.

Samuels et al. ${ }^{20}$ found in a retrospective analysis that the OFA group needed $50 \%$ fewer opioids in postoperative although non-opioid anesthesia did not make any difference. his observation suggests that even exposure to small amounts of opioids intraoperatively increases the need for opioids in the postoperative period.

Toleska and Dimitrovski ${ }^{19}$ found that the opioids needed in the postoperative period were significantly lesser in the OFA group at rest and coughing, compared to the opioid group. On the other hand, Ziemann-Gimmel ${ }^{8}$ found no difference in opioid consumption post-operative for the same VAS scores but did not explain what the post-operative period was compared. The current study shows there was a statistically significant decrease in numbers of patients who developed nausea and vomiting in group II, while no statistically significant difference between both groups by bradycardia. Also, Ziemann-Gimmel ${ }^{8}$ found a significant reduction in PONV in the OFA group even when triple PONV prophylaxis was given to both groups. On the other hand, the study done by Mansour et al. ${ }^{20}$ on 28 obese patients undergoing laparoscopic sleeve gastrectomy found that there were no statistically significant changes among the OFA\& OA groups as regard to postoperative complications in PACU. This may be because all patients received Ranitidine $50 \mathrm{mg}$ as an $\mathrm{H}_{2}$ receptor antagonist, Metoclopramide and dexamethasone as PONV prophylaxis.

Some surgeons have expressed concerns about the safety of the three-port technique, arguing that it may lead to a higher percentage of the bile duct injuries. ${ }^{21}$ However, bile duct injury can be avoided if the gallbladder is gripped at the infundibulum, retracted laterally and dissected at the infundibulum-cystic duct junction rather than cystic ductcommon bile duct junction. ${ }^{22}$

During dissection, an attempt should be made to cut the peritoneum overlying the cystic duct, infundibulum, and body of the gallbladder to relax the gallbladder; the posterior aspect of the cystic duct is then dissected first, before the anterior aspect. This technique enables the surgeon to clip the cystic duct without fear of injury to the bile duct. Several studies demonstrated that less postoperative pain was associated with a reduction in either size or number of ports. ${ }^{23}$ The cost of the 3 port technique was lower, apparently due to the use of fewer surgical ports and related instruments. Also, cosmetic results may have a positive effect, especially in young female patients.

\section{CONCLUSION}

OFA is better than fentanyl for patients who undergo elective laparoscopic cholecystectomy due to perioperative hemodynamic stability, decrease dosages of postoperative analgesics, and decrease PONV. Also, three-port LC is safe and technically feasible when performed by experienced surgeons.

\section{REFERENCES}

1. El Nakeeb A, Mahdy Y, Salem A, et al. Open Cholecystectomy Has a Place in the Laparoscopic Era: a Retrospective Cohort Study. Indian J Surg. 2017; 79 (5):437-443.

2. Calland F, Tanaka K, Foley E et al. Outpatient laparoscopic cholecystectomy: patient outcomes after implementation of a clinical pathway. Ann Surg. 2001; 233(5):704-15.

3. Bisgaard T. Analgesic treatment after Laparoscopic cholecystectomy. Anesthesiology. 2006;104:83546.

4. Woolf CJ, Mannion R. Neuropathic pain: etiology, symptoms, mechanisms, and management. Lancet. 1999; 353: 1959- 1964.

5. Alam S, Hoque H, Saifullah M, et al. The port site and intraperitoneal infiltration of local anesthetics in the reduction of postoperative pain after laparoscopic cholecystectomy. Med Today. 2009; 22: 24-28.

6. Lavand-Homme P. and Steyaert A. opioid-free anesthesia opioid side effects: Tolerance and hyperalgesia. Best Practice \& Research. Clinical Anaesthesiology.2017; 31(4): 487-498.

7. Bakan M, Umutoglu T, Topuz U, et al. Opioid-free total intravenous anesthesia with propofol, dexmedetomidine and lidocaine infusions for laparoscopic cholecystectomy: a prospective, randomized, double-blinded study. Rev Bras Anaesthesiol. 2015; 65(3):191-199.

8. Ziemann P, Goldfarb A, Koppman J, et al. Opioidfree total intravenous anesthesia reduces postoperative nausea and vomiting in bariatric surgery beyond triple prophylaxis. Br J Anaesth. 2014; 112(5):906-11.

9. Mulier JP. Opioid free general anesthesia: A paradigm shift? Rev Esp Anestesiol Reanim. 2017; 64 (8):427430.

10. Sarli L, Iusco D, Gobbi S, et al. Randomized clinical trial of laparoscopic cholecystectomy performed with mini-instruments. Br J Surg. 2003; 90 (11): 13451348.

11. Ryu H, Kang H, Park S, et al. Effects of magnesium sulfate on intraoperative anesthetic requirements and postoperative analgesia in gynecology patients receiving total intravenous anesthesia. $\mathrm{Br} J$ Anaesth 2008; 100 (3): 397-403.

12. De Oliveira S, Almeida $\mathrm{D}$, Benzon $\mathrm{T}$, et al. Perioperative Single-Dose Dexamethasone Systemic for Postoperative pain: A Meta-analysis of Randomized Controlled Trials. The Journal of the American Society of Anesthesiologists. 2011; 115 (3): 575-88.

13. Russo A, Marana E, Viviani D, et al. Diastolic function: the influence of pneumoperitoneum and Trendelenburg positioning during laparoscopic hysterectomy. European Journal of Anaesthesiology. 2009; 26(11): 923-27.

14. Gaszynski T, Czarnik K, Lasziniski Let al. Dexmedetomidine for attenuating hemodynamic response to intubation stimuli in morbidly obese patients anaesthetized using the low-opioid technique: comparison with fentanyl-based general 
anesthesia. Anaesthesiology Intensive Therapy 2016; 48(5): 275-279.

15. Shalaby $M$, Abdalla $M$ and Mahmoud S: Nonopioid versus opioid-based general anesthesia technique for laparoscopic cholecystectomy. Egypt $J$ Hosp Med. 2018; 3 (73) 6206-412.

16. Jan M, Ruben W, Bruno D, et al. A Randomized Controlled, Double-Blind Trial Evaluating the Effect of Opioid-Free Versus Opioid General Anesthesia on Postoperative Pain and Discomfort Measured by the QoR-40 Journal of Clinical Anesthesia and Pain Medicine. 2018; 2 (1):1-6

17. Kataria A, Attri P, Kashyap R. et al. Efficacy of dexmedetomidine and fentanyl on pressor response and pneumoperitoneum in laparoscopic cholecystectomy. Anesthesia, Essays and Researches. 2016; 10 (3): 446.

18. Toleska $\mathrm{M}$ and Dimitrovski A. Is Opioid-Free General Anesthesia More Superior for Postoperative Pain Versus Opioid General Anesthesia in Laparoscopic Cholecystectomy. Pril (Makedon Akad Nauk Umet Odd Med Nauki). 2019; 40(2):81-87. doi: 10.2478/prilozi2019-0018.

19. Samuels D, Abou-Samra A, Dalvi P, et al. Opioidfree Anesthesia Results in Reduced Postoperative Opioid Consumption. J Clin Aneth Pain Med. 2017:1(2):1-3

20. Mansour A, Mahmoud A, Geddawy M. Non-opioid versus opioid-based general anesthesia technique for bariatric surgery: A randomized double-blind study. Saudi J Anaesth. 2013; 7: 387-91.

21. Leggett $P$, Churchman-Winn R, Miller G. Minimizing ports to improve laparoscopic cholecystectomy. Surg Endosc. 2000; 14: 32-36.

22. Litynski S. Profiles in laparoscopy: Mouret, Dubois, and Perissat: the laparoscopic breakthrough in Europe (1987-1988). JSLS. 1999; 3 (2):163-167.

23. Poon $\mathrm{M}$, Chan $\mathrm{W}$, Lee $\mathrm{D}$, et al. Two-port versus four-port laparoscopic cholecystectomy. Surg Endosc. 2003; 17 (10): 1624-1627.
Anesthesia 